\title{
Induction of fibronectin in response to epidermal growth factor is suppressed by silibinin through the inhibition of STAT3 in triple negative breast cancer cells
}

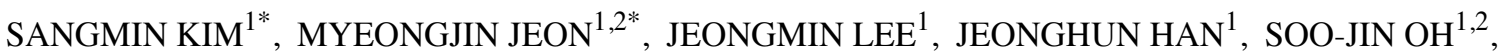 \\ TAEWOO JUNG ${ }^{1,2}$, SEOK JIN NAM ${ }^{1}$, WON HO KIL ${ }^{1}$ and JEONG EON LEE ${ }^{1,2}$ \\ ${ }^{1}$ Department of Surgery, Samsung Medical Center, Sungkyunkwan University School of Medicine, \\ Seoul 135-710; ${ }^{2}$ Department of Health Sciences and Technology, Samsung Advanced Institute \\ for Health Sciences and Technology, Seoul 135-710, Republic of Korea
}

Received April 15, 2014; Accepted July 2, 2014

DOI: $10.3892 /$ or.2014.3450

\begin{abstract}
Fibronectin (FN) plays a major role in cell adhesion, migration and oncogenic transformation. Aberrant FN expression is associated with poor prognosis in various types of cancer, including breast cancer. In this study, we investigated the effect of silibinin on the epidermal growth factor (EGF)-induced FN expression in triple negative breast cancer (TNBC) cells. Our data showed that the levels of FN mRNA and protein expression were dose-dependently increased by EGF in MDA-MB468 and BT20 breast cancer cells. Consequently, EGF-induced FN expression was decreased by the epidermal growth factor receptor (EGFR) inhibitors AG1478 and gefitinib. EGF-induced FN expression was also decreased by MEK1/2, PI3K and STAT3 specific inhibitors. In the present study, we observed for the first time that EGF-induced FN expression was significantly decreased by silibinin treatment in TNBC cells. Furthermore, we found that silibinin suppressed the EGF-induced phosphorylation of STAT3 but not Erk and Akt. Taken together, silibinin downregulated EGF-induced FN expression through the inhibition of STAT3 phosphorylation in TNBC cells. Silibinin may be a promising anticancer drug for the treatment of TNBC.
\end{abstract}

\section{Introduction}

Triple negative breast cancer (TNBC) is an aggressive subtype comprising approximately 15-20\% of breast cancer cases,

Correspondence to: Dr Jeong Eon Lee or Dr Won Ho Kil, Department of Surgery, Samsung Medical Center, Sungkyunkwan University School of Medicine, 50 Irwon-Dong, Gangnam-Gu, Seoul 135-710, Republic of Korea

E-mail: paojlus@hanmail.net

E-mail:wh.kil@samsung.com

${ }^{*}$ Contributed equally

Key words: silibinin, epidermal growth factor receptor, fibronectin, STAT3, triple negative breast cancer with a poor overall prognosis (1). In particular, the level of epidermal growth factor receptor (EGFR) expression has been shown to be markedly increased in TNBC patients, compared to non-TNBC patients (1). EGFR is one of the HER family of receptors and regulates a number of biological responses, such as cell proliferation, invasion and maintenance of the malignant phenotype in breast cancer $(2,3)$. Aberrant EGFR expression is associated with large tumor size, poor differentiation and poor clinical outcomes in breast cancer patients $(4,5)$. The EGF/EGFR signaling pathway triggers the process of epithelial-mesenchymal transition (EMT) to facilitate tumor cell invasion via the induction of mesenchymal markers including fibronectin (FN), Twist, and ZEB $(6,7)$.

$\mathrm{FN}$ is a large adhesive glycoprotein of the extracellular matrix and plays an important role in cell adhesion, growth, migration, differentiation and oncogenic transformation (8-10). It has been shown to be involved in the development of various human cancer types $(10,11)$. In breast cancer patients, the level of FN expression is higher in cases of TNBC (6). Elevated expression of FN contributes to poor clinical outcome in breast cancer patients $(10,11)$. In addition, FN confers resistance to apoptosis induced by standard chemotherapeutic agents (12). However, to date, a correlation between the regulatory mechanism of EGFR and FN has not been fully elucidated in breast cancer.

Silibinin, the major active constituent of silymarin, is isolated from milk thistle seeds and exerts promising anticancer efficacy against various cancer models, such as breast and lung cancer (13-15). In a previous study, we also reported that silibinin downregulates CD44 and MMP-9 expression through inhibition of EGFR phosphorylation in SKBR3 breast cancer cells (16). Thus, we decided to investigate the inhibitory effect of silibinin on the induction of FN expression through the EGF/EGFR signaling pathway in TNBC cells.

The aim of the present study was to evaluate the regulatory mechanism of silibinin on epidermal growth factor (EGF)-induced FN expression in TNBC cells. EGF-induced FN expression was suppressed by the STAT3 inhibitor, Stattic. Silibinin also inhibited EGF-induced FN expression through the suppression of STAT3 activity in MDA-MB468 breast cancer cells, leading to the conclusion that silibinin has 
an inhibitory effect on the EGF/STAT3 signaling pathway, causing suppression of FN expression in TNBC cells. We demonstrated that silibinin may be a promising therapeutic drug for the treatment of TNBC.

\section{Materials and methods}

Reagents. T47D, ZR75-1, MDA468 and BT20 human breast cancer cells were obtained from the American Type Culture Collection (Manassas, VA, USA). MCF7 and MDA-MB231 cells were obtained from the Korea Cell Line Bank (Seoul, Korea). Cell culture media (DMEM and RPMI-1640) and antibiotics were purchased from Life Technologies (Rockville, MD, USA). Fetal bovine serum (FBS) was purchased from HyClone (Logan, UT, USA). Rabbit monoclonal anti-t-EGFR, p-EGFR, t-Akt, p-Akt, t-Erk, p-Erk, t-STAT3, p-STAT3, and FN antibodies were purchased from Epitomics (Burlingame, CA, USA). Mouse monoclonal anti-ER $\alpha$ and secondary horseradish peroxidase (HRP)-conjugated antibodies were purchased from Santa Cruz (Santa Cruz, CA, USA). Gefitinib was purchased from Selleckchem (Houston, TX, USA). AG1478, U0126, LY294002 and Stattic were purchased from Tocris (Ellisville, MO, USA). Silibinin was purchased from Sigma (St. Louis, MO, USA). EGF was purchased from R\&D Systems (Minneapolis, MN, USA).

Cell cultures and chemical treatment. MCF7, MDA-MB231, MDA-MB468 and BT20 breast cancer cells were cultured in DMEM supplemented with $10 \% \mathrm{FBS}, 100 \mathrm{IU} / \mathrm{ml}$ penicillin and $100 \mu \mathrm{g} / \mathrm{ml}$ streptomycin. T47D and ZR75-1 breast cancer cells were cultured in RPMI-1640 supplemented with 10\% FBS, $100 \mathrm{IU} / \mathrm{ml}$ penicillin and $100 \mu \mathrm{g} / \mathrm{ml}$ streptomycin.

Cells were maintained in serum-free culture medium for $24 \mathrm{~h}$, then further incubated with the indicated concentrations of silibinin or various inhibitors, such as gefitinib, AG1478, U0126, LY294002, and Stattic, respectively. Cells were pretreated with silibinin or the other inhibitors for $60 \mathrm{~min}$ prior to treatment with EGF, then treated with EGF for $24 \mathrm{~h}$.

Western blotting. The cell lysates were used in an immunoblot analysis for FN, EGFR, ER- $\alpha$ and $\beta$-actin. The proteins were boiled for $5 \mathrm{~min}$ in Laemmli sample buffer, then electrophoresed in $8 \%$ sodium dodecyl sulfate polyacrylamide (SDS-PAGE) gels. The proteins were transferred to polyvinylidene fluoride (PVDF) membranes, and the membranes were then blocked with $10 \%$ skim milk in Tris-buffered saline (TBS) with $0.01 \%$ Tween-20 (TBS/T) for $15 \mathrm{~min}$. The blots were incubated with the indicated antibodies in TBS/T buffer at $4^{\circ} \mathrm{C}$ overnight. The blots were washed 3 times in TBS/T and were subsequently incubated with an anti-rabbit HRP-conjugated antibody (1:2,000 dilution) in TBS/T buffer. After $1 \mathrm{~h}$ incubation at room temperature (RT), the blots were washed 3 times in TBS/T and $\mathrm{ECL}^{\text {prime }}$ reagent was used for development.

Real-time polymerase chain reaction (PCR). The total RNA was extracted from the treated cells by using the TRIzol reagent (Invitrogen, Carlsbad, CA, USA), according to the manufacturer's protocol. Isolated RNA samples were then used for RT-PCR. Samples (1 $\mu \mathrm{g}$ of total RNA) were reverse-transcribed into cDNA in $20 \mu 1$ reaction volumes using a first-strand cDNA synthesis kit for RT-PCR, according to the manufacturer's instructions (MBI Fermentas; Hanover, MD, USA).

The gene expression was quantified by real-time PCR using a SensiMix SYBR Kit (Bioline Ltd., London, England) and $100 \mathrm{ng}$ of cDNA per reaction. The sequences of the primer sets used for this analysis were: human EGFR (forward, 5'-CAT GTC GAT GGA CTT CCA GA' and reverse, 5'-GGG ACA GCT TGG ATC ACA CT-3'), ER- $\alpha$ (forward, 5'-GAA TCT GCC AAG GAG ACT CG' and reverse, 5'-GGC AGC TCT TCC TCC TGT TT-3'), FN (forward, 5'-CCA CCC CCA TAA GGC ATA GG' and reverse, 5'-GTA GGG GTC AAA GCA CGA GTC ATC-3') and GAPDH as an internal control (forward, 5'-ATT GTT GCC ATC AAT GAC CC-3' and reverse, 5'-AGT AGA GGC AGG GAT GAT GT-3'). An annealing temperature of $60^{\circ} \mathrm{C}$ was used for all the primers. PCRs were performed in a standard 384-well plate format with an ABI 7900HT real-time PCR detection system (Foster City, CA, USA) For data analysis, the raw threshold cycle $(\mathrm{Ct})$ value was first normalized to the housekeeping gene for each sample to get the $\Delta \mathrm{Ct}$. The normalized $\Delta \mathrm{Ct}$ was then calibrated to the control cell samples to get the $\Delta \Delta \mathrm{Ct}$.

Confocal microscopy. Human breast cancer MDA-MB468 and BT20 cells grown on 4-well Lab-Tek chamber slides were allowed to adhere overnight and were then serum-starved for $24 \mathrm{~h}$ before treatment with $50 \mathrm{ng} / \mathrm{ml}$ EGF and/or silibinin for $24 \mathrm{~h}$. Cells were fixed for $20 \mathrm{~min}$ in $4 \%$ paraformaldehyde and incubated at $4^{\circ} \mathrm{C}$ overnight with an anti-FN antibody (B3/D6 clone; DSHB, Iowa, IA, USA), then washed 3 times in PBS. Washed slides were incubated with Alexa Fluor 488-conjugated goat anti-mouse secondary antibody (1:50 dilution) for $60 \mathrm{~min}$ at RT. Cells were then washed in PBS and slides were mounted in Vectashield H-1200/DAPI mounting media (Vector Laboratories, Burlingame, CA, USA). Confocal images were analyzed using an LSM700 confocal laser-scanning microscope (Carl Zeiss, Germany).

Statistical analysis. Statistical values were determined using a Student's t-test. The data are presented as mean values \pm SEM. All quoted P-values were two-tailed and P-values $<0.05$ were considered to indicate statistically significant differences.

\section{Results}

The basal levels of FN $m R N A$ and protein expression are dose-dependently increased by EGF treatment in TNBC breast cancer cells. To investigate the relationship between EGFR and FN expression, we examined the level of EGFR in various breast cancer cells. The basal levels of EGFR and ER- $\alpha$ expression are shown in breast cancer cells in Fig. 1A and B. The basal-like breast cancer cells, MDA-MB468, BT20, and MDA-MB231, had a high level of EGFR mRNA expression (Fig. 1A). In contrast, the luminal type breast cancer cells, MCF7, T47D, and ZR75-1, showed overexpression of ER- $\alpha$ mRNA (Fig. 1A). Consequently, the levels of EGFR and ER- $\alpha$ protein expression in the basal and luminal breast cancer cells were also high, respectively (Fig. 1B). We selected two basal breast cancer cell lines, MDA-MB468 and BT20, to verify the effect of silibinin on EGF-induced FN expression. We treated the cells with the indicated concentrations of EGF for $24 \mathrm{~h}$. 

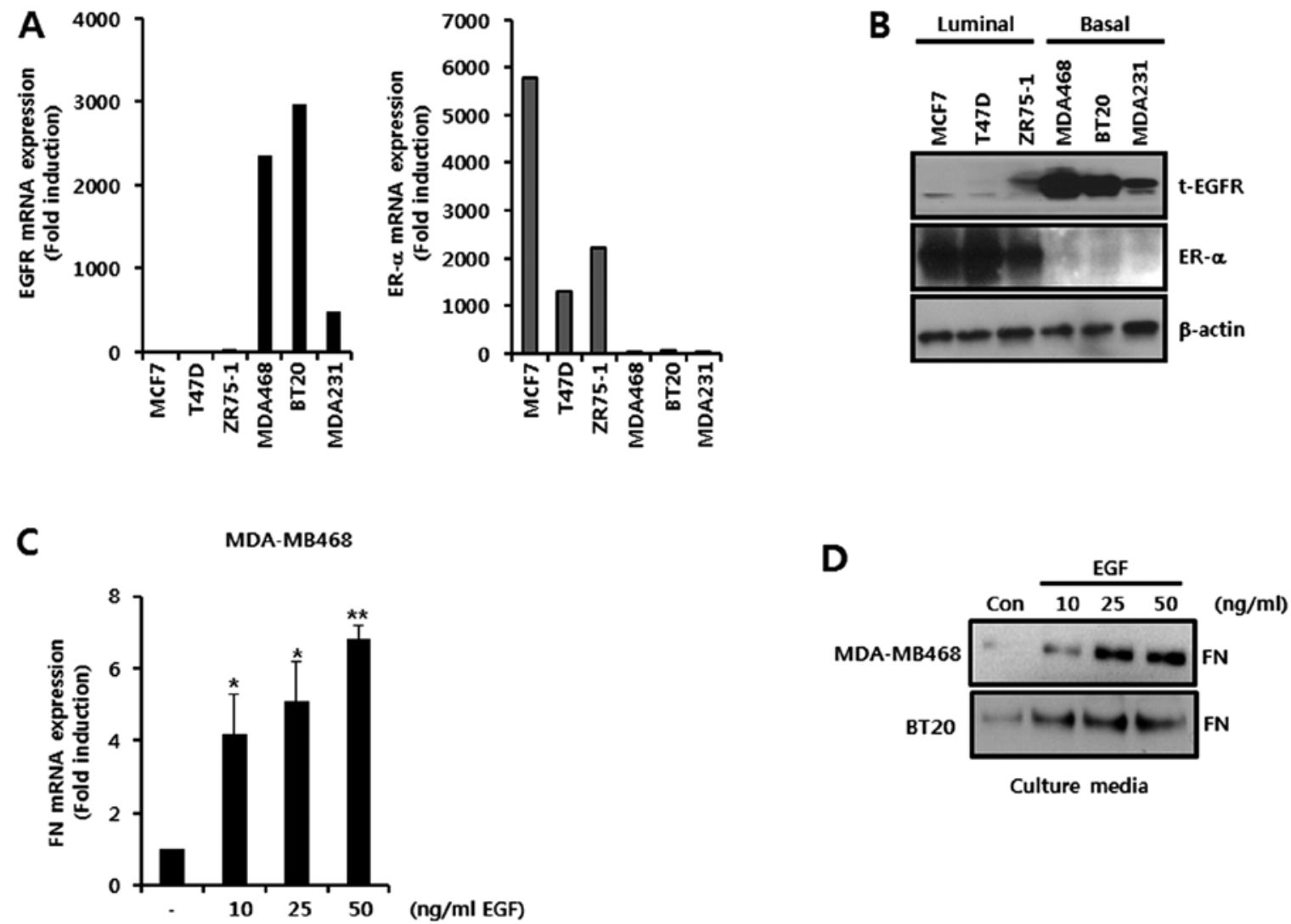

Figure 1. The basal level of FN expression is increased by EGF in a dose-dependent manner in breast cancer cells. (A and B) Levels of EGFR and ER- $\alpha$ expression of breast cancer cells as analyzed by (A) real-time PCR and (B) western blotting, respectively. (C and D) Level of FN mRNA and protein expression, respectively, in serum-starved, EGF-treated cells as analyzed by (C) real-time PCR and (D) western blotting in cell culture media. These results are representative of three independent experiments. The values shown are mean values \pm SEM. ${ }^{*} \mathrm{P}<0.05,{ }^{* *} \mathrm{P}<0.01$ vs. control. FN, fibronectin; Con, control.

Our results showed that the level of FN mRNA expression was dose-dependently increased by EGF in MDA-MB468 cells (Fig. 1C). The level of the FN mRNA expression was significantly increased by $4.2 \pm 1.1$-fold, $5.1 \pm 1.1$-fold, and $6.8 \pm 0.4$-fold of the control levels with EGF concentrations of 10, 25 and $50 \mathrm{ng} / \mathrm{ml}$, respectively (Fig. 1C). Treated under the same conditions, the level of FN protein expression was also shown to be increased in both MDA-MB468 and BT20 cells (Fig. 1D). Based on these results, we demonstrated that EGF triggers expression of both FN mRNA and FN protein in TNBC cells.

EGF-induced FN expression is decreased by EGFR inhibitors, gefitinib and AG1478, in TNBC cells. We examined the effects of the EGFR inhibitors gefitinib and AG1478 on EGF-induced FN expression in TNBC cells. Cells were pretreated with either $10 \mu \mathrm{M}$ gefitinib or $10 \mu \mathrm{M}$ AG1478 for $60 \mathrm{~min}$ and were then treated with $50 \mathrm{ng} / \mathrm{ml}$ of EGF for $24 \mathrm{~h}$. EGF significantly increased the level of FN protein expression in MDA-MB468 and BT20 cells (Fig. 2A). However, EGF-induced FN expression was reduced by treatment with gefitinib and AG1478, respectively, in cell culture media (Fig. 2A). Under the same conditions, EGF-induced FN mRNA expression was significantly decreased by treatment with gefitinib and AG1478, respectively, in MDA-MB468 cells (Fig. 2B). The FN mRNA expression was increased to $6.0 \pm 0.8$-fold that of the control level following treatment with $50 \mathrm{ng} / \mathrm{ml}$ EGF. By contrast,
EGF-induced FN mRNA expression was markedly inhibited to $1.85 \pm 0.25$-fold and $1.05 \pm 0.15$-fold that of the control level in the cells pretreated with gefitinib and AG1478, respectively (Fig. 2B).

We also examined the effects of EGFR inhibitors on EGF-induced EGFR phosphorylation. EGFR phosphorylation peaked $15 \mathrm{~min}$ after EGF treatment. The phosphorylation of EGFR was significantly reduced by the treatment with both gefitinib and AG1478 (Fig. 2C). This shows that the levels of FN protein and mRNA expression in TNBC cells are upregulated by the EGF/EGFR signaling pathway.

Effect of EGFR downstream signaling molecule inhibitors on EGF-induced FN expression in TNBC cells. Next, we investigated the effects of EGFR downstream signaling molecule inhibitors on EGF-induced FN expression in TNBC cells. We pretreated cells with either $10 \mu \mathrm{M}$ UO126 (a MEK1/2 inhibitor), $10 \mu \mathrm{M}$ LY294002 (a PI3K inhibitor), or $10 \mu \mathrm{M}$ Stattic (a STAT3 inhibitor), respectively, for $60 \mathrm{~min}$ prior to treatment with $50 \mathrm{ng} / \mathrm{ml}$ EGF. As shown in Fig. 3A, FN protein expression was significantly increased by EGF in inhibitor-untreated controls. However, EGF-induced FN protein expression was suppressed in the MDA-MB468 and BT20 breast cancer cells that were treated with any of the inhibitors (Fig. 3A). Under the same conditions, the level of FN mRNA expression in response to the addition of EGF was increased by $7.75 \pm 1.3$-fold of the control level (Fig. 3B). However, EGF-induced FN mRNA 
A

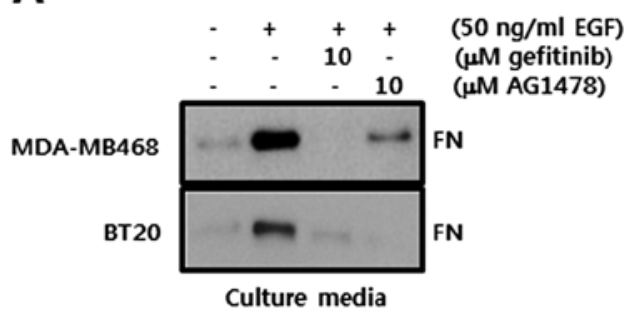

B

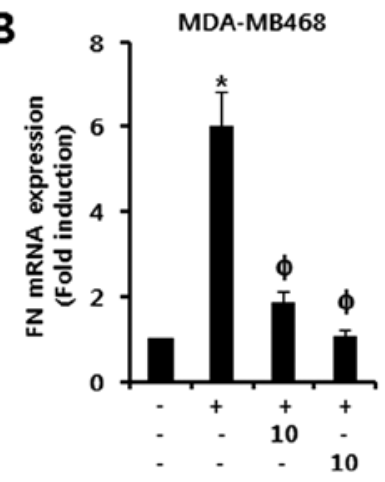

(50 $\mathrm{ng} / \mathrm{ml} \mathrm{EGF)}$ ( $\mu$ M gefitinib)

C

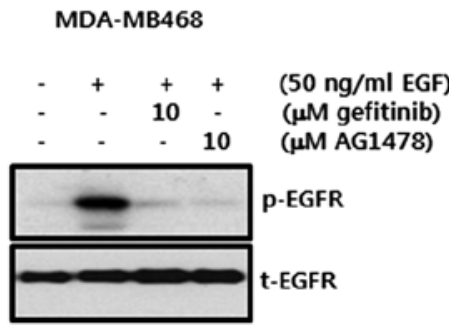

Figure 2. EGF-induced FN expression is reduced by EGFR inhibitors, gefitinib and AG1478, in MDA-MB468 and BT20 breast cancer cells. (A and B) Levels of (A) FN protein expression and (B) mRNA expression in serum-starved cells pretreated with EGFR inhibitors, gefitinib or AG1478 for $30 \mathrm{~min}$ and then treated with $50 \mathrm{ng} / \mathrm{ml} \mathrm{EGF}$ for $24 \mathrm{~h}$, as analyzed by western blotting and real-time PCR, respectively. (C) Western blotting showing the level of p-EGFR and t-EGFR expression in serum-starved cells pretreated with gefitinib or AG1478 for $30 \mathrm{~min}$ and then treated with $50 \mathrm{ng} / \mathrm{ml}$ EGF for $15 \mathrm{~min}$. These results are representative of three independent experiments. The values shown are the means \pm SEM. ${ }^{*} \mathrm{P}<0.05$ vs. control, ${ }^{\phi} \mathrm{P}<0.05$ vs. EGF-treated cells. FN, fibronectin.

expression was reduced to $0.95 \pm 0.2$-fold, $2.0 \pm 0.19$-fold and 2.0 \pm 0.5 -fold of the control level by U0126, LY294002 and Stattic, respectively (Fig. 3B). Furthermore, we verified the effects of U0126, LY294002 and Stattic on EGF-induced STAT3, Akt and Erk phosphorylation, respectively. The phosphorylation of STAT3, Akt and Erk peaked 15 min after EGF treatment. STAT3, Akt and Erk phosphorylation were shown to be decreased by the inhibitors Stattic, LY294002 and U0126, respectively (Fig. 3C). These results demonstrate that EGF-induced FN mRNA and protein expression are mediated through MEK/Erk, PI3K/Akt and STAT3-dependent signaling pathways in TNBC cells.

EGF-induced FN expression is decreased by silibinin in TNBC cells. To test the effect of silibinin on EGF-induced FN expression, we pretreated MDA-MB468 and BT20 cells with 25 and $50 \mu \mathrm{M}$ silibinin for $60 \mathrm{~min}$ prior to treatment with
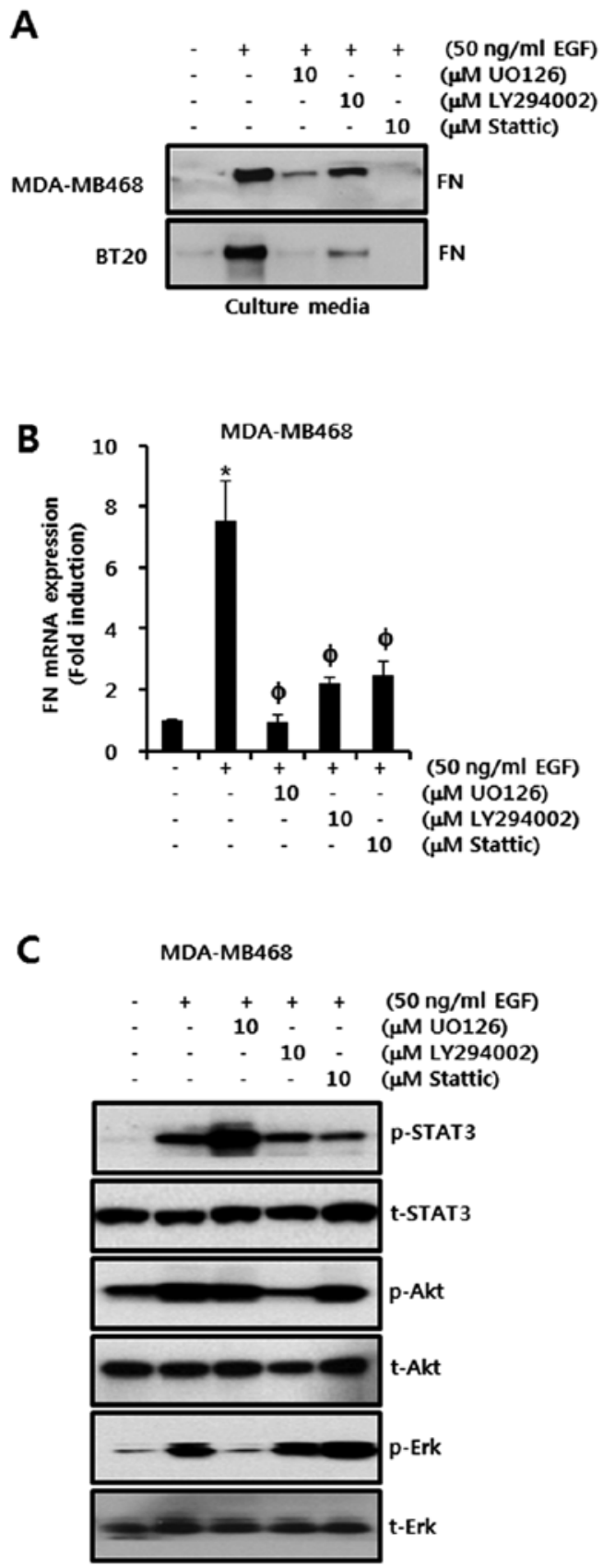

Figure 3. Effect of EGFR downstream signaling molecule inhibitors on EGFinduced FN expression in TNBC cells. (A and B) Levels of (A) FN protein and (B) mRNA expression in serum-starved cells, pretreated with $10 \mu \mathrm{M}$ UO126, $10 \mu \mathrm{M} \mathrm{LY} 294002$ and $10 \mu \mathrm{M}$ Stattic, respectively, then incubated with $50 \mathrm{ng} / \mathrm{ml}$ EGF for $24 \mathrm{~h}$ as analyzed by western blotting and real-time PCR, respectively. (C) Levels of STAT3, Akt and Erk protein expression in serum-starved cells, pretreated with U0126, LY294002 and Stattic, respectively, then treated with EGF for $15 \mathrm{~min}$ as analyzed by western blotting. These results are representative of three independent experiments. The values shown are the means \pm SEM. ${ }^{*} \mathrm{P}<0.05$ vs. control, ${ }^{\phi} \mathrm{P}<0.05$ vs. EGF-treated cells. FN, fibronectin.

$50 \mathrm{ng} / \mathrm{ml}$ EGF. After $24 \mathrm{~h}$, we harvested the cell culture media and cell lysates. Our results indicated that the level of FN protein expression increased in both MDA-MB468 and BT20 breast cancer cells in response to treatment with EGF (Fig. 4A). However, the level of EGF-induced FN protein expression was reduced by silibinin in a dose-dependent manner in both cell culture media and whole cell lysates (Fig. 4A). Under the 


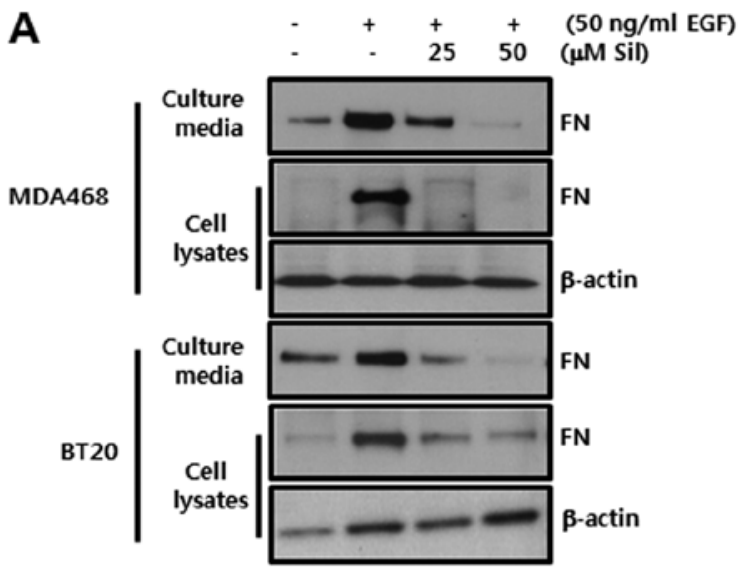

B

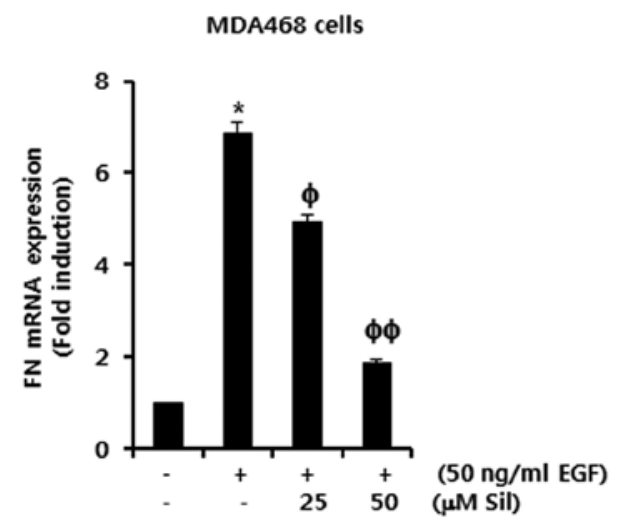

C

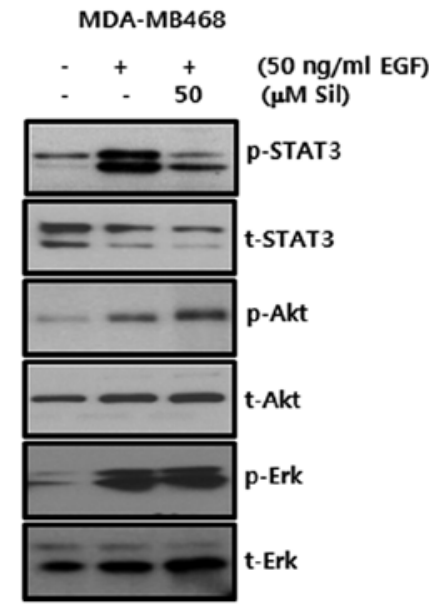

Figure 4. Silibinin suppresses EGF-induced FN expression through the inhibition of STAT3 activity in MDA-MB468 and BT20 breast cancer cells. (A and B) Levels of (A) FN protein and (B) mRNA expression in serum-starved cells pretreated with silibinin then treated with EGF, as analyzed by western blotting and real-time PCR, respectively. (C) Levels of STAT3, Akt and Erk protein expression in serum-starved cells pretreated with silibinin and treated with EGF for $15 \mathrm{~min}$, as analyzed by western blotting. These results are representative of three independent experiments. The values shown are the means \pm SEM. ${ }^{*} \mathrm{P}<0.05$ vs. control, ${ }^{\phi} \mathrm{P}<0.05,{ }^{\phi \phi} \mathrm{P}<0.01$ vs. EGF-treated cells. FN, fibronectin.

same conditions, we also investigated the inhibitory effects of silibinin on EGF-induced FN mRNA expression. As expected, EGF-induced FN mRNA expression was dose-dependently inhibited in MDA-MB468 breast cancer cells by treatment with silibinin (Fig. 4B). The level of FN mRNA expression was increased by 6.86 -fold of the control level by the addition of $50 \mathrm{ng} / \mathrm{ml}$ of EGF. However, the induction of FN mRNA expression by addition of EGF was decreased to 4.92-fold and 1.88 -fold of the control level by treatment with 25 and $50 \mu \mathrm{M}$ of silibinin, respectively (Fig. 4B).

Finally, we investigated the regulatory mechanism of silibinin on EGF-induced FN expression in MDA-MB468 cells. Cells were pretreated with the indicated concentration of silibinin for $60 \mathrm{~min}$ and then treated with EGF for $15 \mathrm{~min}$. The phosphorylation of the EGFR downstream signaling molecules, STAT3, Akt and Erk, was increased by the addition of EGF in silibinin-untreated controls (Fig. 4C). Notably, when we examined the inhibitory effect of silibinin on the activation of these three signaling pathways, we observed that only EGF-induced STAT3 phosphorylation was markedly reduced by silibinin. The phosphorylation of Akt and Erk was not significantly affected (Fig. 4C). These results show that silibinin abolished the EGF-induced FN expression in a similar manner to the STAT3 inhibitor in MDA-MB468 and BT20 breast cancer cells. Therefore, we demonstrated that silibinin suppresses EGF-induced FN expression via the inhibition of STAT3 phosphorylation in TNBC cells.

\section{Discussion}

The TNBC subtype has the poorest prognosis among breast cancer subtypes $(1,17)$ due to limited treatment options and a lack of clinically established targeted molecular therapies. TNBC has a markedly increased level of EGFR expression, resulting in aggressive metastasis and a poor prognosis, as defined by its low five-year survival and high recurrence rates after adjuvant therapy (1). EGFR inhibitors, such as monoclonal antibodies (cetuximab) and small molecule inhibitors (gefitinib), have been used in the treatment of TNBC, for which there are currently no specific targeted therapies (18).

EGF stimulates cell growth, proliferation and differentiation through binding to its receptor EGFR (5). High expression of EGFR within primary tumors is associated with a poor clinical outcome in human cancers, and EGFR is frequently overexpressed in TNBC patients (19-23). In addition, the EGF/ EGFR signaling pathway is a well-known inducer of the EMT process in several types of human cancer (24). EGF leads to EMT-like changes, including upregulation of mesenchymal markers and downregulation of epithelial markers $(25,26)$. Consistent with these reports, our results showed that the levels of EGFR expression were significantly increased in TNBC cells, and EGF-induced FN expression was increased in a dose-dependent manner in TNBC cells.

The EGF/EGFR complex mainly activates various downstream signaling pathways, such as MEK/ERK, PI3K/Akt and JAK/STAT3, in malignant human cancer cells $(27,28)$. The EGFR inhibitor AG1478, MEK1/2 inhibitor PD98059, and p38MAPK inhibitor SB203580 completely abolished TGF- $\beta$-mediated FN expression (29). Heparin-binding EGF-like growth factor (HB-EGF), a heparin-binding member of the EGF family, significantly increases the level of FN expression in mesangial cells (30). In contrast, neutralizing anti-HB-EGF antibody completely blocks FN expression (30). 
In accordance with these reports, our results showed that EGF also affects the level of FN expression in TNBC cells. In TNBC cells, EGF-induced FN expression was suppressed by UO126 (a MEK1/2 inhibitor) and LY294002 (a PI3K inhibitor). In this study, to the best of our knowledge, we are the first to demonstrate that EGF-induced FN expression is significantly decreased by a STAT3 inhibitor, Stattic. These results suggest that STAT3 is a new pathway involved in the regulation of EGF-induced FN expression.

The level of FN expression is regulated by a variety of growth factors, such as TGF- $\beta$, PDGF and EGF, which have been implicated in developmental processes (29). Highly expressed FN levels in breast tumor tissues have been correlated with tumor malignancy and the poor prognosis of breast cancer patients $(31,32)$. In addition, $\mathrm{FN}$ expression has been shown to be involved in the epithelial-mesenchymal transition (EMT) process, which occurs during development and has been linked to cancer $(25,26)$. Growth factors, such as EGF and TGF- $\beta$, can promote the EMT triggering of specific signaling networks $(6,33-36)$. Our results showed that FN expression in TNBC cells is higher than that of other breast cancer cells (data not shown). FN expression in response to EGF was significantly decreased by the EGFR inhibitors, AG1478 and gefitinib, in TNBC cells.

Silibinin has multifunctional activities including the suppression of cell invasion, inflammation, the induction of apoptosis in various cancer cells such as breast cancer cells (14-16,37). In a previous study, we reported that silibinin suppresses the level of COX-2 and VEGF through the inhibition of the Raf/MEK/ ERK pathway in breast cancer cells $(14,15)$. Here, we focused on the regulatory mechanism of silibinin on EGF-induced FN expression in TNBC cells. We observed that silibinin inhibited EGF-induced expression of FN and the phosphorylation of STAT3 in breast cancer cells. In addition, we observed that EGF-induced FN expression was decreased by a specific STAT3 inhibitor, Stattic. Based on these results, we conclude that silibinin prevents EGF-induced FN expression through the inhibition of STAT3 phosphorylation in TNBC cells.

In the present study, we conclusively verified the regulatory mechanism of silibinin in EGF-induced FN expression in TNBC cells. EGF-induced signaling molecules, MEK, PI3K and STAT3, play an important role in the regulation of FN expression in TNBC cells. However, silibinin suppressed only EGF-induced STAT3 phosphorylation, not phosphorylation in the MEK/ERK and PI3K/Akt pathway. Hence, we demonstrated that silibinin suppresses EGF-induced FN expression through the inhibition of STAT3 in TNBC cells. We therefore suggest that silibinin could be used as a potential candidate drug for the treatment of TNBC, for which there are currently no specific targeted therapies.

\section{Acknowledgements}

This study was supported by grants from the Samsung Biomedical Research Institute (SMR1120321), the Korea Research Foundation, funded by the Korean Government, (NRF-2012R1A1B4000493) and the Korea Health Technology R\&D Project, through the Korea Health Industry Development Institute(KHIDI), funded by the Ministry of Health \& Welfare, Republic of Korea (HI09C1552).

\section{References}

1. Dent R, Trudeau M, Pritchard KI, Hanna WM, Kahn HK, Sawka CA, Lickley LA, Rawlinson E, Sun P and Narod SA: Triple-negative breast cancer: clinical features and patterns of recurrence. Clin Cancer Res 13: 4429-4434, 2007.

2. Ullrich A and Schlessinger J: Signal transduction by receptors with tyrosine kinase activity. Cell 61: 203-212, 1990.

3. Baselga $J$ and Arteaga CL: Critical update and emerging trends in epidermal growth factor receptor targeting in cancer. J Clin Oncol 23: 2445-2459, 2005.

4. Sainsbury JR, Farndon JR, Needham GK, Malcolm AJ and Harris AL: Epidermal-growth-factor receptor status as predictor of early recurrence of and death from breast cancer. Lancet 1: 1398-1402, 1987.

5. Salomon DS, Brandt R, Ciardiello F and Normanno N: Epidermal growth factor-related peptides and their receptors in human malignancies. Crit Rev Oncol Hematol 19: 183-232, 1995.

6. Balanis N, Wendt MK, Schiemann BJ, Wang Z, Schiemann WP and Carlin CR: Epithelial to mesenchymal transition promotes breast cancer progression via a fibronectin-dependent STAT3 signaling pathway. J Biol Chem 288: 17954-17967, 2013.

7. Wendt MK, Smith JA and Schiemann WP: Transforming growth factor-beta-induced epithelial-mesenchymal transition facilitates epidermal growth factor-dependent breast cancer progression. Oncogene 29: 6485-6498, 2010.

8. Pankov R and Yamada KM: Fibronectin at a glance. J Cell Sci 115: 3861-3863, 2002.

9. Ritzenthaler JD, Han S and Roman J: Stimulation of lung carcinoma cell growth by fibronectin-integrin signalling. Mol Biosyst 4: 1160-1169, 2008.

10. Fernandez-Garcia B, Eiro N, Marin L, Gonzalez-Reyes S, Gonzalez LO, Lamelas ML and Vizoso FJ: Expression and prognostic significance of fibronectin and matrix metalloproteases in breast cancer metastasis. Histopathology: 512-522, 2013.

11. Bae YK, Kim A, Kim MK, Choi JE, Kang SH and Lee SJ: Fibronectin expression in carcinoma cells correlates with tumor aggressiveness and poor clinical outcome in patients with invasive breast cancer. Hum Pathol 44: 2028-2037, 2013.

12. Rintoul RC and Sethi T: Extracellular matrix regulation of drug resistance in small-cell lung cancer. Clin Sci 102: 417-424, 2002.

13. Sharma G, Singh RP, Chan DC and Agarwal R: Silibinin induces growth inhibition and apoptotic cell death in human lung carcinoma cells. Anticancer Res 23: 2649-2655, 2003.

14. Kim S, Choi JH, Lim HI, Lee SK, Kim WW, Kim JS, Kim JH, Choe JH, Yang JH, Nam SJ and Lee JE: Silibinin prevents TPA-induced MMP-9 expression and VEGF secretion by inactivation of the Raf/MEK/ERK pathway in MCF-7 human breast cancer cells. Phytomedicine 16: 573-580, 2009.

15. Kim S, Kim SH, Hur SM, Lee SK, Kim WW, Kim JS, Kim JH, Choe JH, Nam SJ, Lee JE and Yang JH: Silibinin prevents TPA-induced MMP-9 expression by downregulation of COX-2 in human breast cancer cells. J Ethnopharmacol 126: 252-257, 2009.

16. Kim S, Han J, Kim JS, Kim JH, Choe JH, Yang JH, Nam SJ and Lee JE: Silibinin suppresses EGFR ligand-induced CD44 expression through inhibition of EGFR activity in breast cancer cells. Anticancer Res 31: 3767-3773, 2011.

17. Lehmann BD, Bauer JA, Chen X, Sanders ME, Chakravarthy AB, Shyr Y and Pietenpol JA: Identification of human triple-negative breast cancer subtypes and preclinical models for selection of targeted therapies. J Clin Invest 121: 2750-2767, 2011.

18. Ferraro DA, Gaborit N, Maron R, Cohen-Dvashi H, Porat Z, Pareja F, Lavi S, Lindzen M, Ben-Chetrit N, Sela M and Yarden Y: Inhibition of triple-negative breast cancer models by combinations of antibodies to EGFR. Proc Natl Acad Sci USA 110: 1815-1820, 2013.

19. Choi J, Jung WH and Koo JS: Clinicopathologic features of molecular subtypes of triple negative breast cancer based on immunohistochemical markers. Histol Histopathol 27: 1481-1493, 2012.

20. Gumuskaya B, Alper M, Hucumenoglu S, Altundag K, Uner A and Guler G: EGFR expression and gene copy number in triple-negative breast carcinoma. Cancer Genet Cytogenet 203: 222-229, 2010.

21. Rakha EA, El-Sayed ME, Green AR, Lee AH, Robertson JF and Ellis IO: Prognostic markers in triple-negative breast cancer. Cancer 109: 25-32, 2007. 
22. Martin V, Botta F, Zanellato E, Molinari F, Crippa S, Mazzucchelli L and Frattini M: Molecular characterization of EGFR and EGFR-downstream pathways in triple negative breast carcinomas with basal like features. Histol and Histopathol 27: 785-792, 2012.

23. Liu D, He J, Yuan Z, Wang S, Peng R, Shi Y, Teng X and Qin T: EGFR expression correlates with decreased disease-free survival in triple-negative breast cancer: a retrospective analysis based on a tissue microarray. Med Oncol 29: 401-405, 2012.

24. Ackland ML, Newgreen DF, Fridman M, Waltham MC, Arvanitis A, Minichiello J, Price JT and Thompson EW: Epidermal growth factor-induced epithelio-mesenchymal transition in human breast carcinoma cells. Lab Invest 83: 435-448, 2003.

25. Sun X, Fa P, Cui Z, Xia Y, Sun L, Li Z, Tang A, Gui Y and Cai Z: The EDA-containing cellular fibronectin induces epithelialmesenchymal transition in lung cancer cells through integrin $\alpha 9 \beta 1-$ mediated activation of PI3-K/AKT and Erk1/2. Carcinogenesis 35: 184-191, 2014

26. Sudo T, Iwaya T, Nishida N, Sawada G, Takahashi Y, Ishibashi M, Shibata K, Fujita H, Shirouzu K, Mori M and Mimori K: Expression of mesenchymal markers vimentin and fibronectin: the clinical significance in esophageal squamous cell carcinoma. Ann Surg Oncol 20: S324-S335, 2013.

27. Kim S, Choi JH, Lim HI, Lee SK, Kim WW, Cho S, Kim JS Kim JH, Choe JH, Nam SJ, Lee JE and Yang JH: EGF-induced MMP-9 expression is mediated by the JAK3/ERK pathway, but not by the JAK3/STAT-3 pathway in a SKBR3 breast cancer cell line. Cell Signal 21: 892-898, 2009.

28. Kim S, Han J, Lee SK, Koo M, Cho DH, Bae SY, Choi MY, Kim JS, Kim JH, Choe JH, Yang JH, Nam SJ and Lee JE: Smad7 acts as a negative regulator of the epidermal growth factor (EGF) signaling pathway in breast cancer cells. Cancer Lett 314 $147-154,2012$

29. Hayashida T, Poncelet AC, Hubchak SC and Schnaper HW: TGF-beta1 activates MAP kinase in human mesangial cells: a possible role in collagen expression. Kidney Int 56: 1710-1720, 1999.
30. Uchiyama-Tanaka Y,Matsubara H,Mori Y,Kosaki A,KishimotoN, Amano K, Higashiyama $S$ and Iwasaka T: Involvement of HB-EGF and EGF receptor transactivation in TGF-beta-mediated fibronectin expression in mesangial cells. Kidney Int 62: 799-808, 2002.

31. Helleman J, Jansen MP, Ruigrok-Ritstier K, van Staveren IL, Look MP, Meijer-van Gelder ME, Sieuwerts AM, Klijn JG, Sleijfer S, Foekens JA and Berns EM: Association of an extracellular matrix gene cluster with breast cancer prognosis and endocrine therapy response. Clin Cancer Res 14: 5555-5564, 2008.

32. Yao ES, Zhang H, Chen YY, Lee B, Chew K, Moore D and Park C: Increased beta1 integrin is associated with decreased survival in invasive breast cancer. Cancer Res 67: 659-664, 2007.

33. Vergara D, Valente CM, Tinelli A, Siciliano C, Lorusso V, Acierno R, Giovinazzo G, Santino A, Storelli C and Maffia M: Resveratrol inhibits the epidermal growth factor-induced epithelial mesenchymal transition in MCF-7 cells. Cancer Lett 310: 1-8, 2011.

34. Grande M, Franzen A, Karlsson JO, Ericson LE, Heldin NE and Nilsson M: Transforming growth factor-beta and epidermal growth factor synergistically stimulate epithelial to mesenchymal transition (EMT) through a MEK-dependent mechanism in primary cultured pig thyrocytes. J Cell Sci 115: 4227-4236, 2002.

35. Lo HW, Hsu SC, Xia W, Cao X, Shih JY, Wei Y, Abbruzzese JL, Hortobagyi GN and Hung MC: Epidermal growth factor receptor cooperates with signal transducer and activator of transcription 3 to induce epithelial-mesenchymal transition in cancer cells via upregulation of TWIST gene expression. Cancer Res 67: 9066-9076, 2007.

36. Kasai H, Allen JT, Mason RM, Kamimura T and Zhang Z: TGF-beta1 induces human alveolar epithelial to mesenchymal cell transition (EMT). Respir Res 6: 56, 2005.

37. Cheung CW, Gibbons N, Johnson DW and Nicol DL: Silibinin - a promising new treatment for cancer. Anticancer Agents Med Chem 10: 186-195, 2010. 